\title{
Spontaneous Temporary Remission in Primary CNS Lymphoma
}

\author{
Michael Rubin, Israel Libman, Marie-Laure Brisson, \\ Marvin Goldenberg and Steven Brem
}

\begin{abstract}
We report a case of primary CNS lymphoma in which complete, though temporary, spontaneous clinical and radiologic remission occurred. This is the first such case report to our knowledge.

RÉSUMÉ: Rémission spontanée temporaire d'un lymphome primaire du SNC Nous rapportons un cas de lymphome primaire du SNC chez qui nous avons observé une rémission clinique et radiologique spontanée complète, quoique temporaire. Ceci constitue, à notre connaissance, le premier compte-rendu d'un tel cas.
\end{abstract}

Can. J. Neurol. Sci. 1987: 14:175-177

Primary lymphoma of the CNS is a rare disease, representing less than $2 \%$ of all extranodal lymphomas. 'It is a highly malignant neoplasm. Average survival is 3.3 months with supportive care alone ${ }^{2}$ and up to 45 months following excision and radiation therapy. ${ }^{3}$ Recent reports, however, suggest variability in the prognosis, possibly corresponding to diverse responses to therapy. ${ }^{4}$ Case reports document both steroid-induced remis$\operatorname{sion}^{5.6}$ and spontaneous, though incomplete regression. ${ }^{7}$

We report a case of complete, spontaneous remission of primary CNS lymphoma that occurred within 27 weeks of onset and which, by CT and clinical data, lasted approximately one year before relapse. To our knowledge, this is the first such reported case in the literature and it lends further support to the notion that CNS lymphoma is a heterogeneous disorder. At the very least, it is clearly capricious in its natural history.

\section{Case Report}

A 56 year-old woman was admitted to our institution because of hemiparesis and an abnormal CT scan.

She was last well twenty-one months earlier when she awoke one morning with right-sided weakness which progressed over two days and then stabilized. Examination revealed a healthy looking 56 yearold female, with a normal general physical examination. Neurological examination disclosed a mild, spastic right hemiparesis.
The following laboratory tests were normal: complete blood count (CBC), chest $X$-ray (CXR), electrocardiogram (EKG), sequential multiple analysis computer (SMAC), echocardiogram, serum protein electro pheresis (SPEP), VDRL, anti-nuclear antibody (ANA). Electroencephalogram (EEG) revealed minimal asymmetry over the centro-temporal regions. An infused CT scan showed a round, $1 \mathrm{~cm}$ enhancing nodule in the left fronto-parietal region that was not seen on the plain CT (Figure 1). There was considerable surrounding white matter edema but no midline shift. An angiogram showed no tumour mass or abnormal vessels.

Because of the critical location of the tumour, a biopsy was not performed, and the patient was sent home. At follow-up in six weeks she felt perfectly well and her examination was normal. CT showed a new enhancing dense nodule in the left hemisphere, several centimetres below and slightly lateral to the original nodule. At the level of the original nodule, the CT had returned to normal (Figure 2). She was followed as an outpatient and four months later was seen again. She was well and again examination was normal. CT scan at this time had completely normalized. She continued to do well.

She returned one year later, with a three week history of increasing left sided weakness, accompanied by mild occipital headache. General physical examination revealed early papilledema and mild spastic left hemiparesis. Normal lab tests included CBC, SMAC, CXR, EKG. echocardiogram, and VDRL. EEG showed mild to moderate irregularity over the right centro-temporal region. CT scan showed multiple enhancing lesions in the right cerebral and cerebellar hemispheres, with edema and mass effect. Lumbar puncture yielded clear CSF with 67 red blood cells and 6 lymphocytes per $c c$. The lymphocytes were small and mature with rare cells showing atypical features. CSF protein

From the Departments of Neuroscience (Drs. Rubin, Libman, Brem), Pathology (Dr. Brisson), and Neuroradiology (Dr. Goldenberg). The Sir Mortimer B. Davis-Jewish General Hospital and McGill University, Montreal

Received September 18, 1986. Accepted January 13, 1987

Reprint requests to: Dr. I. Libman. Sir Mortimer B. Davis-Jewish General Hospital. 3755 Cote Ste. Catherine, Montreal, Quebec, Canada H3T IE2 


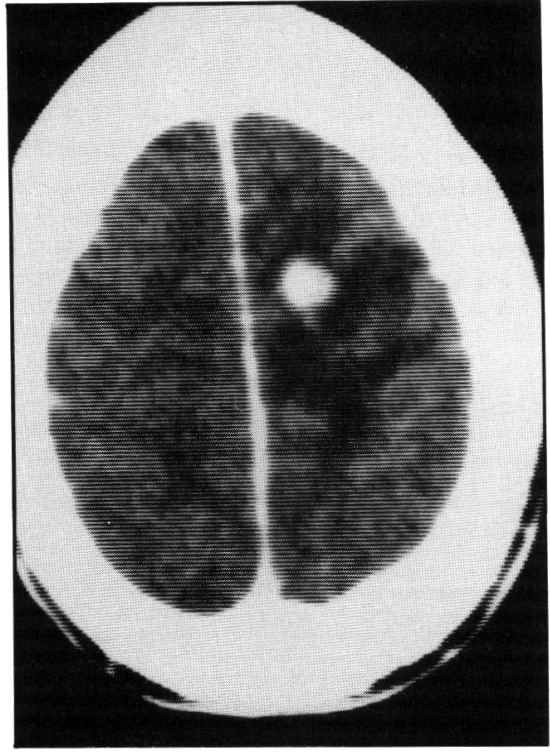

Figure I - Infused CT scan done at onset of illness shows a round $I \mathrm{~cm}$ enhanced nodule in left fronto-parietal region with surrounding edema. No other lesions are noted.

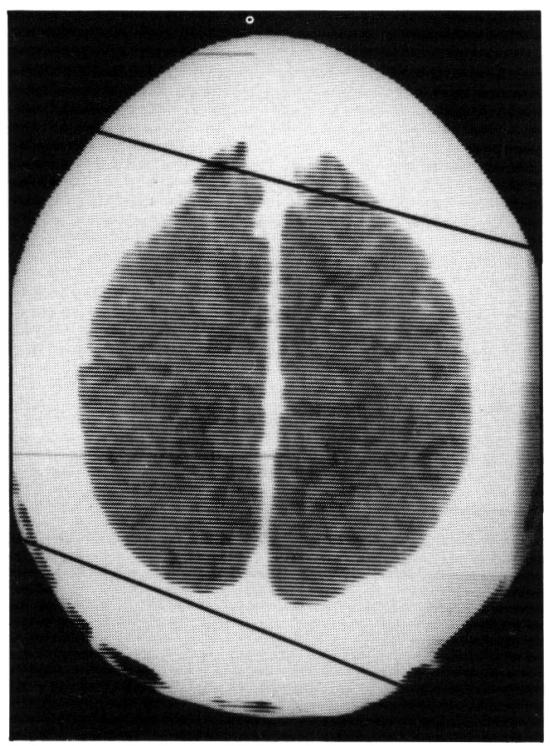

Figure 2 - At the level of the original nodule the $C T$ scan has returned to normal 8 weeks after initial scan (lines are artefacts).

was $124 \mathrm{mg} / \mathrm{dl}$. IGG was $13.3 \%$ with negative oligoclonal banding. Sugar was $70 \mathrm{mg} / \mathrm{dl}$. A hematology consultant felt there was no evidence to suggest a diagnosis of lymphoma and the patient was discharged with a tentative diagnosis of multiple sclerosis and was started on tapering doses of prednisone at $80 \mathrm{mg}$ per day. Seen in follow-up four weeks later, the patient felt well. Her neurological examination was unremarkable and a follow up CT was arranged. Her steroids were discontinued.

Three days later, left hemiparesis recurred. Her general practitioner restarted prednisone at $40 \mathrm{mg}$ per day, but weakness progressed and the patient began to experience gait ataxia and headache. She was readmitted. Examination again revealed bilateral papilledema and left spastic hemiparesis. CT scans with and without infusion showed the high right fronto-parietal lesion to be larger (Figure $3 \mathrm{~A}$ ). There was a new small left frontal enhancing lesion (Figure 3B). Decadron was started and a decompressive right frontal biopsy and excision of mass was performed.

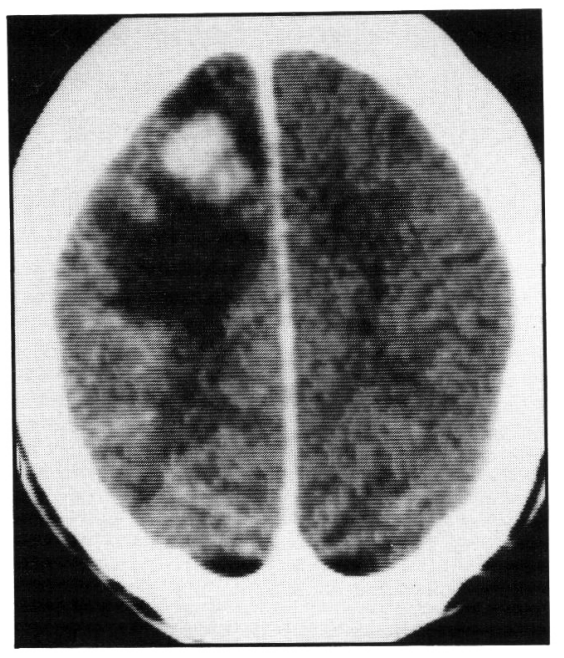

A

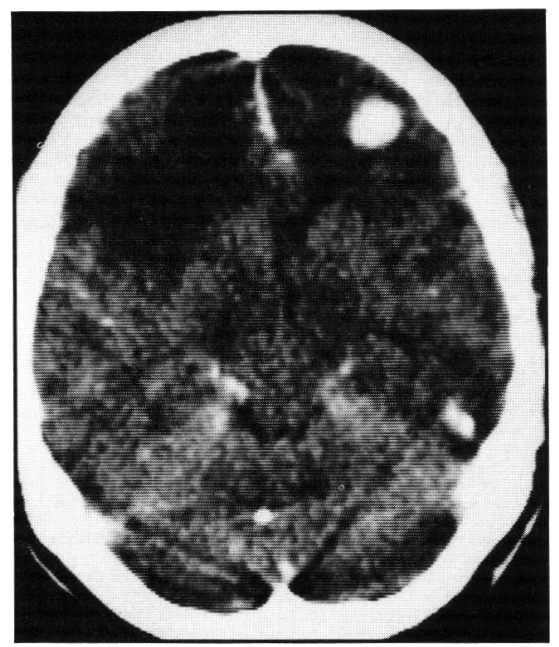

B

Figure $3 A-$ Highrightfrontallesion. Considerable edema is present.

Figure $3 B$ - Shows a new enhancing nodule in the left inferior frontal region. Both $3 A$ and $3 B$ done approximately 20 months after initial presentation.

Pathologic study of the biopsy under light microscopy showed a diffuse infiltration of large cell type with high mitotoic activity (Figure 4). Accumulation of cells in perivascular spaces was prominent in some fragments (Figure 4 insert). Glial fibrillary acidic protein (GFAP) stain performed by peroxidase anti-peroxidase (PAP) technique on formalinfixed tissue was negative except for a few residual non-neoplastic astrocytes. Pyroninophilia was demonstrated by methyl green pyronine (MGP) stain. Immunofluorescence on snap frozen tissue showed monoclonal positivity for IgM-Lambda consistent with a B cell lymphoma. The overall interpretation was, therefore, of diffuse lymphoma immunoblastic B cell type (IgM-Lambda).

The patient did well post-operatively, and was discharged on steroids. Radiotherapy was arranged on an outpatient basis.

\section{Discussion}

The intracerebral mass lesion with which this patient initially presented was in retrospect, probably, CNS lymphoma. It seemed to disappear spontaneously within six weeks, and was replaced by a second enhancing lesion, which also seemed to have disappeared spontaneously, on follow-up CT scan, four months later. This remission lasted thirteen months, at which time, recurrence occurred both in the same location, and at 


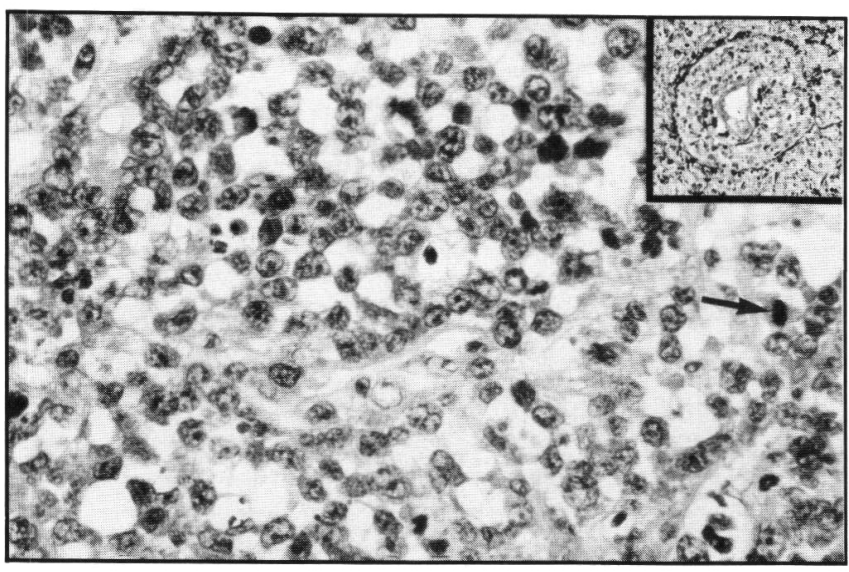

Figure 4-Photomicrograph of the tumour showing a diffuse monotonous cell population. These cells have round uncleaved vesicular nuclei, distinct, often prominent nucleoli and mitotic figures are present (arrow). The insert shows accumulation of cells in the perivascular space (H\&E $\times 40)$.

other sites within the brain. Steroids induced clinical remission, but upon discontinuance the patient relapsed with new lesions, and biopsy yielded a diagnosis of lymphoma. To our knowledge, this is the first reported case of apparently complete spontaneous remission in CNS lymphoma.

Clinical remission has been observed, albeit rarely, with systemic lymphoma.${ }^{8,9,10}$ With CNS lymphoma, partial regression has been documented to occur spontaneously, ${ }^{7}$ and on several occasions, a complete, albeit temporary remission has also been observed, though always in connection with steroid therapy. ${ }^{5.6}$ Steroid induced remission is not surprising, given the fact that tumours, and specifically lymphoma cells, may be sensitive to glucocorticoid killing activity. ${ }^{11.12 .13}$ Recent studies indicate that up to $50 \%$ of lymphoma patients will obtain a partial remission given two weeks of therapy with dexamethasone alone. ${ }^{14,15}$ The mechanism of glucocorticoid anti-neoplastic activity appears to be mediated through glucocorticoid receptors which are located in the cytosol. ${ }^{16}$ The glucocorticoidreceptor complex has a special affinity for nuclear DNA. After binding to the DNA, mRNA is transcribed which codes for certain proteins which are the actual tumourolytic effectors. A correlation has been found between the level of glucocorticoid receptor and the response to dexamethasone in lymphoma.

What is totally unexpected however, is that despite any treatment, a mass should disappear. The mechanism for this can only be speculated upon at this time. Recently, reports have suggested that there is considerable variability in the activity of CNS lymphoma. ${ }^{4}$ The same tumour may be fatal in a matter of weeks, despite any therapeutic manoeuver, whereas in other instances, the patient may survive a few years. Why this should occur is unclear.
One suggestion is that the tumour invades or outgrows its blood supply, and autoinfarcts. Alternatively, serendipitous embolic or thrombotic infarction of the tumour might occur. Neither of these scenarios is highly likely in our patient, where a mass disappeared on two separate occasions. Further study will be necessary to delineate the full spectrum of activity of this tumour and to understand just why it should, in a fortunate few, disappear without apparent cause.

\section{ACKNOWLEDGEMENT}

We gratefully acknowledge the technical assistance of Ms. Anne Shirley Luck.

\section{REFERENCES}

1. Freeman C, Berg JW, Cutler SJ. Occurrence and prognosis of extranodal lymphomas. Cancer 1972: 29: 252-60.

2. Henry JM, Heffner RR, Dillard SH, et al. Primary malignant lymphomas of the central nervous system. Cancer $1974 ; 34$ : 1293-1302.

3. Burnstein S, Kernohan J, Uihlein A. Neoplasms of the reticuloendothelial system of the brain. Cancer 1963: 16:290-305.

4. Schaumburg HH, Plank CR, Adams RD. The reticulum cell sarcoma microglioma group of brain tumours: A consideration of their clinical features and therapy. Brain 1972; 95: 199-212.

5. Williams RS, Crowell RM, Fisher CM, et al. Clinical and radiologic remission in reticulum cell sarcoma of the brain. Arch Neurol 1979; 36: 206-10.

6. Singh A, Strobos RJ, Singh BM, et al. Steroid induced remissions in CNS lymphoma. Neurology (NY) 1982: 32: 1267-71.

7. Weingarten KL, Zimmerman RD, Leeds NE. Spontaneous regression of intracerebral lymphoma. Radiology 1983; 149: 721-24.

8. Minot GR, Isaacs R. Lymphoblastoma (malignant lymphoma): age and sex incidence, duration of disease, and the effect of roentgen ray and radium irradiation and surgery. JAMA 1926: 86: $1185-89,1265-70$

9. Gall EA, Mallory TB. Malignant lymphoma: a clinical pathological survey of 618 cases. Am J Pathol 1942; 18: 381-429.

10. Everson TC. Spontaneous regression of human tumours. In: Ariel IM, ed. Progress in Clinical Cancer. Vol 3 New York, Grune and Stratton Inc. 1967: 79-95.

11. Baxter JD, Harris AW, Tomkins GM, et al. Glucocorticoid receptors in lymphoma cells in culture: relationship to glucocorticoid killing activity. Science 1971: 171: 189-91.

12. Sherbet GV, Lakshmi MS, Haddad SK. Does dexamethasone inhibit the growth of human gliomas? J Neurosurg 1977: 47: 864-70.

13. Claman HN. Corticosteroids and lymphoid cells. N Engl J Med 1972; 287: 388-97.

14. Bloomfield CD, Smith KA, Peterson BA, et al. In vitro glucocorticoid studies for predicting response to glucocorticoid therapy in adults with malignant lymphoma. Lancet 1980; 1: 952-56.

15. Bloomfield CD, Smith KA, Peterson BA, et al. In vitro glucocorticoid studies in human lymphoma: clinical and biologic significance. J Steroid Biochem 1981; 15: 275-84.

16. Bloomfield CD. Glucocorticoid receptors in leukemia and lymphoma. $\mathrm{J}$ Clin Oncol 1984; 2: 323-28. 